\title{
Providing Care and Facing Death: Nursing During Ebola Outbreaks in Central Africa
}

\author{
BONNIE L. HEWLETT, PhD, RN \\ Oregon State University \\ BARRY S. HEWLETT, PhD \\ Washington State University
}

Few studies have focused on describing the experiences of health care workers during rapid killing epidemics. In this article, the views and experiences of nurses during three outbreaks of Ebola hemorrhagic fever (EHF) in Central Africa are examined. These three outbreaks occurred in Kikwit, Democratic Republic of Congo (DRC, 1995); Gulu, Uganda (2000-2001); and Republic of Congo (ROC, 2003). Openended and semistructured interviews with individuals and small groups were conducted during the outbreaks in Uganda and ROC; data from DRC are extracted from published sources. Three key themes emerged from the interviews: (a) lack of protective gear, basic equipment, and other resources necessary to provide care, especially during the early phases of the outbreaks; (b) stigmatization by family, coworkers, and community; and (c) exceptional commitment to the nursing profession in a context where the lives of the health care workers were in jeopardy.

Keywords: Ebola hemorrhagic fever; nurses; explanatory models; stigmatization; epidemics; Uganda; Democratic Republic of Congo (DRC); Republic of Congo (ROC)

My children were afraid of me, they were afraid to touch me. I wanted to quit but I knew that if I quit all the others would want to quit. My husband was afraid and feared me, he asked me where my clothes washing pot was, he did not want to use it. We ate on separate plates and used separate silverware.

$$
\text { -Ugandan Nurse }
$$

Journal of Transcultural Nursing, Vol. 16 No. 4, October 2005 289-297 DOI: $310.1177 / 1043659605278935$

(C) 2005 Sage Publications

\begin{abstract}
The greatest worry at work was that I had no protective gear in place. At the beginning of the isolation, there were only gloves, no masks.
\end{abstract}

—Ugandan Nurse

Outbreaks of Ebola hemorrhagic fever (EHF), one of the deadliest viruses known, occurred in Central Africa in 1995, 2000 , and again in 2003. The above quotes illustrate three key themes that emerged from interviews with nurses who provided care at great personal risk for patients with EHF. These key themes were lack of resources, stigmatization, and exceptional professional commitment.

Some of the earliest victims of EHF were the nurses themselves. The 1995 Democratic Republic of the Congo (DRC) outbreak was devastating for health care workers - of the 250 individuals who died, 47 (approximately 20\%) were health care professionals (Guimard et al., 1999). In the 2000-2001 Uganda outbreak, 224 individuals fell victim to this frightening and devastating virus; 14 of those who died were nurses (World Health Organization [WHO], 2003). As the disease unfolded in 2003 in a rural district in the Republic of Congo (ROC), the fatalities among health care workers ( 3 of 128 deaths) were fewer, as the epidemic had occurred the previous year in the same region and local people cared for those infected with EHF at home in their rural villages, rather than taking them to distant clinics (Formenty et al., 2003).

The nurses and other health care workers labored under extraordinarily difficult conditions, as they often do in many parts of Africa, lacking such basic infection control tools as bleach, soap, and gloves. Their colleagues, community, and families often shunned them. Their clothes were burned, and their homes destroyed. Yet these nurses chose to stay on 
behalf of a sense of duty and their perception of what it means to be a caregiver.

The major themes that emerged from interviews of nurses caring for patients of EHF are present, in some measure, at all times for health care workers laboring in the cities and rural villages of Africa. Resources are generally always inadequate. For many professionals, working without pay is the standard not the exception. Stigmatization, discrimination, and belief in sorcery are prevalent attitudes not only concerning Ebola but also HIV and other infectious diseases. The major difference between the Ebola epidemic and others, such as the HIV epidemic, is that the nurses, doctors, Red Cross volunteers, and other health care workers risked their own lives to a much greater degree to provide care, than in other epidemics.

The aim of the current study was to provide new insights and background into a major health care crisis that made headlines around the world. No other study could be found that examined the experiences of nurses during an Ebola epidemic. The findings reported in this article are taken from a larger study of survivors of EHF, health care workers, community members, and traditional healers in villages with large numbers of EHF cases. Only the experiences of nurses caring for EHF patients and their families are reported here.

\section{BACKGROUND}

\section{EHF}

Many regions throughout Africa have been hit hard by such diseases as HIV, malaria, tuberculosis, dysentery, and measles, to name just a few, with thousands of people dying every day from preventable illnesses. What distinguishes this disease is that it remains so mysterious. EHF belongs to one of the only known virus families of which scientists have such a profound lack of understanding: the vector or reservoir, the very source of infection, is unknown; the exact modes of transmission are not always identified; there is no known cure, vaccine, or treatment for this usually fatal infectious disease; and little is known of the natural history of the virus, much less the resulting diseases, their pathogenesis, and detailed virology (Peters \& LeDue, 1999, p. ix). Health care workers can offer only palliative care in response to the devastating effects of this virus.

And it is a rapid killer. EHF is a virulent viral disease causing death in $50 \%$ to $90 \%$ of clinically diagnosed cases. The disease itself is caused by infection with the Ebola virus, named after a river in the DRC (formerly Zaire) in Central Africa, where it was first recognized. The virus is one of two members of a family of RNA filoviridae viruses. Ebola is not just one virus; there are four subtypes, two of which are responsible for more than $95 \%$ of all cases; Ebola-Zaire $(80 \%$ to $90 \%$ case fatality rate) and Ebola-Sudan (40\% to $50 \%$ case mortality rate).
Transmission of the Ebola virus occurs by direct contact with the blood, secretions, or organs of infected persons or animals and is characterized by the sudden onset of fever, weakness, muscle pain, headache, and sore throat. This is followed by vomiting, diarrhea, rash, limited kidney and liver functions, and internal and external bleeding, though hemorrhaging generally occurs in less than $50 \%$ of cases. Because no specific treatment or vaccine currently exists for EHF, the patient usually dies within 6 days of becoming symptomatic (Hewlett \& Amola, 2003; WHO, 2003). Those infected in Uganda with the Sudan subtype had a $50 \%$ chance of dying within 1 week of becoming symptomatic. For those victims of the DRC and ROC outbreaks, the mortality rates were higher. In these cases, individuals with the Zairian subtype of this viral disease had an $80 \%$ to $90 \%$ fatality risk.

When an outbreak has been identified, attempts to contain its spread must be instituted quickly. It is estimated that each victim potentially comes into contact with an average of 10 people. These 10 people are identified as contact cases, who then need to be monitored for signs and symptoms of the disease. Monitoring is complicated by the fact that often the initial symptoms of headache, fever, diarrhea, and vomiting mimic those of malaria, dysentery, or influenza, which are commonly found throughout Central Africa. When the contact cases are nurses who subsequently become infected, the potential for a nosocomial spread increases dramatically.

\section{Regions of Research}

The research was conducted in three regions: (a) Kikwit, DRC; Uganda; and the ROC. Table 1 lists the characteristics of each site, the number of cases and fatalities, and the measures used to terminate the outbreaks.

\section{METHOD}

A diversity of research methods were utilized in the current study. During the outbreaks in Uganda and the ROC, open-ended and semistructured interviews were conducted with a broad range of individuals and focus groups (e.g., see Hewlett \& Amola, 2003, for details of these diverse methods). The cultural models described below are based on these multiple methods whereas the data on nurses and health care workers presented are a subset of these data. In Uganda, semistructured interviews were conducted with three nurses working in the isolation units, three nurses who survived Ebola, and two focus groups of nurses and health care workers. In Congo, interviews were conducted with four nurses, one focus group of nurses, and one focus group of health care workers. Both studies were commissioned by WHO, Geneva. In the DRC, data are based on published descriptions and interviews with nurses. A medical anthropology report on the Ugandan outbreak by Kabananukye (2001) was also utilized.

Finally, it is important to mention a few things about the social context of working during outbreaks in Uganda and 
TABLE 1

Recent Outbreaks of Ebola Hemorrhagic Fever (EHF) in Central Africa

\begin{tabular}{|c|c|c|c|}
\hline Dates of Outbreak Studied & $\begin{array}{l}\text { Democratic Republic } \\
\text { Of Congo (DRC) } \\
\text { January - June } 1995\end{array}$ & $\begin{array}{c}\text { Uganda } \\
\text { August } 2000 \text { - January } 2001\end{array}$ & $\begin{array}{c}\text { Republic of Congo (ROC) } \\
\text { December } 2002 \text { - April } 2003\end{array}$ \\
\hline Site of outbreak & $\begin{array}{l}\text { Primarily city of Kikwit: urban area } \\
400 \mathrm{~km} \text { from Kinshasa (capital) }\end{array}$ & $\begin{array}{l}\text { Primarily city of Gulu, urban area; } \\
\text { secondary outbreaks in Masindi } \\
\text { (6\% cases) and Mbarara ( } 1 \% \text { cases) }\end{array}$ & $\begin{array}{l}\text { Primarily villages of Kéllé and } \\
\text { Mbomo, rural area }\end{array}$ \\
\hline Population of region & 200,000 & 470,000 in Gulu District & 12,700 \\
\hline Primary ethnic group(s) affected & Several ethnic groups & Primarily Acholi & $\begin{array}{l}\text { Mbeti, Mboko, Kota Mongome, } \\
\text { Bakola }\end{array}$ \\
\hline Number of EHF cases & 316 cases & 425 cases & 143 cases \\
\hline Fatality rate & $81 \%$ & $53 \%$ & $90 \%$ \\
\hline $\begin{array}{l}\text { Number of health care worker } \\
\text { deaths (\% of total deaths) }\end{array}$ & $80(25)$ & $14(6)$ & $3(2)$ \\
\hline $\begin{array}{l}\text { Measures contributing to EHF } \\
\text { termination }\end{array}$ & $\begin{array}{l}\text { Initiation of infection control mea- } \\
\text { sures (barriers); rapid identification } \\
\text { of cases; health education efforts }\end{array}$ & $\begin{array}{l}\text { Infection control measures; early rec- } \\
\text { ognition of outbreak; initiation of } \\
\text { case finding; hospitalization of } \\
\text { infected patients in facilities with } \\
\text { strict infection control; community } \\
\text { education; establishment of burial } \\
\text { teams; education of health care } \\
\text { workers }\end{array}$ & $\begin{array}{l}\text { Relative isolation of rural area; previ- } \\
\text { ous experience with Ebola; early } \\
\text { use of previously learned disease } \\
\text { control techniques }\end{array}$ \\
\hline
\end{tabular}

Congo. The governments banned or discouraged all travel into or out of the area, borders were closed, school and church services were cancelled, all large public events were banned, for example, dances, night clubs, soccer matches, large funerals (small burial rituals were allowed), and even traditional greeting by shaking hands was banned. Community members in Uganda and Congo developed alternative greetings-in Congo, individuals snapped their fingers, and in Uganda individuals bumped elbows together. The consumption of any type of game meat was discouraged. Fear, tension, and uncertainty existed within the community; however, most people went about their lives, conducting their various daily tasks in spite of the outbreak and the above noted restrictions (Hewlett \& Amola, 2003).

We hope that by identifying the key themes emerging from our interviews with the local health care workers during the Ebola outbreaks, the current study demonstrates the need for health care workers worldwide to understand the importance of local cultural models of disease, identifying beliefs and practices that can amplify or help control infectious epidemics, and encouraging the integration of local cultural practices into biomedical control efforts.

\section{RESULTS}

\section{Cultural Models}

Before describing the feelings and views of nurses, it is important to explain the results of research on local cultural models for EHF. The models described below are based on diverse qualitative and quantitative methods (see Hewlett \& Amola, 2003, for details), with several different groups, including nurses. A cultural model (Kleinman, 1980) is an individual's socially transmitted knowledge and explanation for a particular illness and includes his or her own ideas about signs, symptoms, cause, treatments, prevention, and prognosis about the illness. Nurses and other health care workers are trained in the biomedical cultural model but may have knowledge of alternative cultural models based on their ethnic or family background. Biomedical training tends to view alternative cultural models as something to overcome, at best, or primitive and backwards, at worst. Local nurses in Africa tend to be embarrassed by their so-called traditional beliefs, and international health workers often view local beliefs and practices as problematic. We hope the descriptions of cultural models demonstrate to local nurses that there may be value in these beliefs and practices and that nurses who come from the international community can build on the models in providing care.

It is essential that nurses and other health workers are sensitive to these cultural models because individuals tend to have strong feelings about their perceptions; furthermore, the models influence treatment seeking and compliance with biomedical care and control of disease. Providing care and treatment for a particular disease is often based on regularly negotiating biomedical and other cultural models. We collected data on cultural models for Uganda and ROC; however, data do not exist for earlier outbreaks, including the DRC outbreak discussed in this article. 
Uganda. Initially in Uganda, the symptoms of EHF were viewed by the Acholi as a so-called regular illness, and a variety of modern drugs, that is, chloroquine for fever and/or malaria or antibiotics for bloody diarrhea, and indigenous cures, such as herbs and traditional healers, were utilized. After multiple deaths occurred within the same family, elders sought the assistance of a traditional healer to remove yat (poisons) that could be infecting the household.

To understand yat and responses to EHF, it is important to describe the concept of jok (spirits or gods), which is common to many Nilotic-speaking peoples, including the Acholi. Many different types of jok exist. They have names and can often be found near bodies of water, mountains, and natural salt licks for cattle. The jok, or spirits, are generally benevolent as they provide and control resources. However, they can also cause harm if they are not shown respect. Spiritual life reflects and reinforces the central values in Acholi life, that of deference and respect of others. Jok are like elders in the community; they are listened to, obeyed without question, and given gifts as a demonstration of respect. The healer's jok communicates with the jok causing the problems to see what it wants in terms of respect; generally this means the sacrifice of goats, sheep, or other animals. The jok works through the healer's special metal spear, identifying the yat in the household area. The yat is burned, taken away by the healer or even placed in a bucket of Jik (bleach) to destroy the poison. Hypothetically, when the yat is removed and respect is demonstrated, the deaths should stop. This did not happen with EHF as family members in both of these villages continued to die (Hewlett \& Amola, 2003).

When yat extraction failed, it was no longer seen as a regular illness and became classified as gemo. Gemo is a spirit that comes suddenly and rapidly, like the wind, and affects many people, often causing multiple deaths. When an illness is identified as gemo, a protocol for its prevention and control is implemented that is quite different from the treatment and control of other illnesses: isolating the patient, identifying houses and villages with individuals with gemo, having survivors care for the patients, no dances or large public gatherings, and burying the dead far from the village (people typically bury family members next to their homes). From a biomedical perspective, the protocol is a broad-spectrum approach to epidemic control (see Hewlett \& Amola, 2003, for details).

The biomedical cultural model for Ebola was introduced in Uganda after many people had already died and local people understood EHF as gemo. A broad range of excellent health educators arrived from Kampala, the capital, and explained that it was a "disease of contact" and that families had to limit physical contact, especially with the washing and burial of the dead; a few were already taking these precautions because they viewed it as gemo.

The nurses, and indeed most people in the area, appeared to have integrated the two cultural models, that is, biomedical and gemo. Nurses emphasized the biomedical model; however, many of them participated in local rituals to chase gemo away. Nurses talked to their patients about gemo but did not mention it to members of the international team because they thought they would be viewed as primitive and uneducated. Rural communities turned to the yat and gemo cultural models but did not hesitate to purchase tetracycline and other medicines to treat cases of Ebola. As often happens, there is a fluidity of movement between cultural models.

ROC. Changes in cultural models in ROC were somewhat similar. Initially, the symptoms were viewed as a regular illness and people responded to them with biomedical and indigenous treatments. After several deaths occurred, local people began to attribute the deaths to sorcery (ekundu). Ekundu is often thought to be behind the rapid death of an adult who had appeared to be in good health. A sorcerer sends an object containing a powerful spirit into the victim, causing pain and inflammation. Only a traditional healer can see the object and identify the sorcerer. When identified and the object destroyed, the person's health will improve. The communities adhered to the sorcery explanation until several people in the family had died and people became aware that gorillas and other primates were dying from the same disease. Attempts by traditional healers to cure ekundu also failed as the fatalities continued.

When we arrived, most people we talked with indicated that Ebola was a type of natural illness (ekono) that comes like the wind, (opepe), attacks many, and often leads to death. It is essentially the local term for a killer epidemic. The origin of opepe is like other ekono, that is, it comes from those things that are dirty; however, it is different in other ways, in that it comes with the air and attacks many people at once. The primary way to prevent an attack of opepe is to move to a forest camp or camp in the fields, as this would prevent an attack from the air. Like ekono, people felt opepe illnesses were transmitted by contact with infected individuals. The local people listed ways to prevent and control opepe infection: isolate the patient, close and monitor the village, and go into the forest if possible. Because of the hard work of Red Cross volunteers, the biomedical model also became known soon after the outbreak had occurred.

In summary, knowledge of local and biomedical models contributed to the eventual control of the outbreak. Local nurses and other health care workers were aware of these models and were in a position to negotiate the cultural models more readily than members of the international teams sent to control the outbreaks. Unfortunately, those ascribing to the biomedical model tended to reject or view indigenous knowledge and practices systems (i.e., culture) as problematic and something to overcome because they were seen as serving to amplify rather then control the outbreaks. Often health educators and local, national, and international medical personnel were not aware or did not consider the possibility that 
existing traditional beliefs and practices actually contribute to EHF control efforts.

Cultural models are important to understand; however, it is also important to listen to, and build on the views and experiences of nurses during these outbreaks. The previous section was based on interviews with a wide range of community members within an outbreak area whereas the following sections are based upon the words, views, and feelings of nurses and other health care workers. Three general themes from nurses emerged: lack of resources, stigmatization, and commitment to the profession. They are presented separately; however, there is enormous overlap and integration of the three themes.

\section{Lack of Resources and Political Economy}

The problem is not how many patients, but what of the materials? We have to deal with the problem, the problem of space we can manage, but how can we manage with the problem of not enough materials to protect ourselves when we care for the patients? (Congolese nurse)

It is important to understand, as the nurses suggested in the interviews in Uganda and ROC, and as Garrett (2000, p. 88) pointed out, that the etiology of this fatal disease was, and continues to be, as much political and economic as it is biological. In any profit economy, economics influence policies of health care and disease control that are often addressed within the realm of politics and profit. Medical discourses of disease hold a privileged position of authority that allow differential access to resources. As the nurses themselves explained,

The greatest worry at work was that I had no protective gear in place. At the beginning of the isolation, there were only gloves, no masks. (Ugandan nurse)

We are afraid. We question our safety. But we are obliged to our patients. (Congolese nurse)

During outbreaks of Ebola, as with HIV, measles, malaria, tuberculosis (TB), dysentery, and other infectious and parasitic diseases, the economics of caregiving for the health care workers include the lack of equipment, medicine, and pay. There are often no masks, gowns, boots, soap, bleach, medical equipment, beds, and little medicine. There was, and remains to be, little money to be put toward this simple equipment, protective gear, medicines, or salaries. Then, as now, throughout much of Africa, health care workers often work without pay, or payment of their meager salaries is delayed for months, sometimes years.

Kikwit, DRC. During the 1995 Ebola epidemic in Kikwit, with its $80 \%$ fatality rate, nosocomial transmission played a major role in the spread of the disease. The health care system in DRC was impaired. Guimard et al. (1999) reported that during the outbreak at the Kikwit hospital, "The hygienic working conditions were far from ideal" (p. 269). There was no running water, no electricity, and no working waste disposal system. Nursing care involving invasive procedures was carried out often without protective gear. Most nursing care, in fact, was given by family members who, at times, slept in the same bed as the patient (pp. 268-273). There was a lack of disposable medical material and protective equipment. Even simple and basic supplies, such as bedpans, bandages, thermometers, disposable needles, and medicines, were nonexistent or in short supply. In addition, the medical staff had gone underpaid or not paid at all for some time prior to and during the epidemic. In fact, as Garrett (2000) reported, the nation's civil servants, including more than $95 \%$ of DRC's physicians and nurses had gone unpaid since 1991 (p. 58). Under such conditions, the protection of the hospital staff, the care of patients, and the containment of this killer epidemic were difficult. Indeed, as Garrett wrote, "Ebola spread in Kikwit because the most basic, essential elements of public health were non-existent. . . . Ebola haunted Zaire (DRC) because of corruption and political repression" (p. 59); that is, Ebola spread because of an "inevitable outcome of disgraceful disconcern-even disdain-for the health" of the people of DRC (p. 59).

Uganda. Similar issues concerning the economics of care were commonly expressed by Uganda nurses where nosocomial transmission was also common. As a head nurse from Uganda explained,

The greatest worry (at work) was that I had no protective gear in place. At the beginning of the isolation, there were only gloves, no masks, and I took blood for malaria. My colleagues feared us the most (those who worked in the isolation ward) at the beginning. It has cost me with my colleagues. After a long time the government came up with the idea to give us money as motivation to work. Some of my colleagues saw this as being desperate for money, if we took it. (Ugandan nurse)

The victims of Ebola would tell me that they got Ebola from nursing their sick mother, or going to a funeral of the infected dead, or from going to the hospital. The suggestions to improve this situation would be to build a new structure for isolation. To stock all the hospital with protective gear. To have continuous training of health workers, and we need continuous training on barrier nursing. There needs to be continuous health education to the community. The people had bad feelings and anger of not being informed of death, there was no planning in place, no proper communication for the families. But in the epidemic it was difficult to arrange, when there were ten deaths a day. (Ugandan nurse)

This political-economic dimension of the nurses' understanding of Ebola was, as noted, echoed many times in these geographically different areas. It reflected their own concerns and the concerns of the community. The economic problems were, and continue to be, complex and multifaceted. Some 
lost property as the people would burn plantations, clothing, beddings, and household property of Ebola suspects in an attempt to reduce the rate of transmission of Ebola. This was because of, in part, a misunderstanding arising from a WHO video that showed the burning of patient beds.

Traditional healers had their homes and properties destroyed for treating Ebola victims, as did identified suspects who were also threatened with death if they did not leave the area (Kabananukye, 2001, p. 40). Children were often left on their own after the death of their parents and had to either be absorbed into already large extended families, or were left to fend on their own, often heading their own households, fighting to hold onto their families' property and having no way with which to support themselves and their siblings.

Markets, medical clinics, restaurants, bars, and other businesses were closed for fear of touching contaminated money or from the fear of the risk of transmission through the touch of a victim of Ebola. The Uganda Muslim Supreme Council issued a statement that the Saudi Arabian government had banned all travelers from Uganda "based upon suspicions that they could carry the deadly Ebola virus" (Kabananukye, 2001, pp. i-vi). An entire country was stigmatized, feared, and as a result suffered terrific economic loss.

$R O C$. It was this same economics and politics of care that greatly affected the nurses, doctors, and Red Cross Volunteers in their response to the Ebola epidemic in ROC. One nurse interviewed in Congo had this to say:

I feel that our training (isolation and barrier nursing technique) is adequate, as we learned from last year ... (an epidemic of EHF had occurred the year before in the same general area) ... and no nurses have died, but we do not have enough equipment to deal with the epidemic. Our protection is questionable. There is only a small amount of materials for those who have direct care of the Ebola patient(s), but the rest of the personnel do not have sufficient protective material available for them. We have 2 nurses per shift, and there are three shifts per 24 hours ( 6 a.m. - 12 p.m., 12-6 p.m., 6 p.m. -6 a.m.). We have one nurse to provide the care and one to act as a "control" to make sure that the proper procedures are observed, but we are afraid. We question our safety. But we are obliged to our patients.

In a rural hospital in the ROC, there were only two rooms said to be ready to be used as isolation rooms. Both were small and ill-equipped, with only a mattressless metal cot and bucket, broken windows, and no running water or indoor toilets. The nurses were asked whether they could provide care for more than one new admission at a time. "No, even with two patients it is difficult. There is not enough rooms or materials, it is a worry for us." This same nurse later voiced this concern at the Crises Committee meeting organized by the Ministry of Health director sent to oversee the epidemic in this area. The nurse went on to explain,
The problem is not how many patients, but what of the materials? We have to deal with the problem. The problem of space we can manage, but how can we manage with the problem of not enough materials to protect ourselves when we care for the patients?

The nurses stressed several times they felt they could deal with the lack of space for multiple admissions but only if they had sufficient materials. They also noted a need for medicine to be given for other illnesses that they frequently saw such as malaria, parasites, and upper respiratory infections: "These are especially needed during the epidemic to rule out other illnesses which present with many of the same initial symptoms as Ebola, but these medicines are lacking. We do not even have enough medicine for common illnesses." The nurses explained, too, that during the epidemic people have little money, and unless they were a contact case (who does not have to pay for medicines), they were required to purchase their own medicine. However, the care of patients with common illnesses seemed to be nonexistent during the epidemic, because of, in part, a lack of medicine and people feared coming to the clinic.

The nurses in Mbomo were fortunate because they had been trained in the method of triage care and suffered no fatalities. The health care workers in Kéllé, the other district in this area, were also relatively more fortunate in that only three nurses died, as many people had stayed away from the hospital and cared for their sick in their own homes and villages. Nosocomial transmission, this time, played only a minor role.

Medical anthropologists often use political economic, "structural violence," or critical medical anthropology theories to explain the lack of resources in the developing world (Farmer, 2005). The nurses and health care workers in these areas may not understand the details of the global economicpolitical system and how it contributes to inequality; however, they clearly expressed and comprehended that access to these resources from national and international sources influenced the spread and control of Ebola.

Political and economic forces often seem to exist beyond the disease. However, these forces greatly affect the perception of disease and the responses to it, by the country, the community, the nurses, and their patients. Issues and problems of health, illness, and treatment need to be examined in terms of the interaction between the macrolevel of the political economy, the national level of political and economic structure, the institutional level of the health care system, and the community level of belief and action.

\section{Stigmatization}

My colleagues feared us the most (those who worked in the isolation ward) at the beginning. It has cost me with my colleagues. (Ugandan nurse)

People were afraid to meet with the health care workers because they thought we would give them Ebola. Many 
people who were sick with other illness would stay home because Ebola was at the hospital. The people were afraid of any illness, so they neglected those sick in their families, they did not give food and let them lie alone, neglected. The people did not know how Ebola was spread, by flies, the air, maybe by the water? (Ugandan nurse)

Our clothes were burned, and our children kept away from us, our families shunned us and were afraid of us. My children would not shake my hand and told me not to ride my bike home (from work) because it might carry Ebola. I wanted to rinse the bike with bleach, but I just walked home because people were afraid. The rejection and the stigmatization were the strongest at the start of the outbreak when there were so many deaths. (Ugandan nurse)

Kikwit, DRC. Anyone associated with Ebola was likely to have experienced stigmatization. During one point of the outbreak in DRC, local people thought Ebola originated with the medical staff working in the hospital. All those who had died had been in a hospital. Therefore, the people reasoned, it was the health care workers who were killing people. This rumor eventually disappeared; however, at the height of the epidemic, it was a rumor that demoralized the local health care workers and made it difficult for nurses at home and in the community. The nurses and doctors had to deal with not only a panicked and fearful public, essentially absent public health and medical resources, but also they themselves were seen as agents of death. Garrett (2000) recounted an interview with one nurse who had contacted Ebola and was hospitalized, "She was sick for three weeks. Nobody would touch her. Everybody was afraid" (p. 114). She recovered but felt tremendous guilt at having survived, whereas so many of her colleagues had not.

Uganda. In Uganda, those suspected of having Ebola were evacuated from their homes and villages, sprayed with chemicals, some even as they held their babies. Victims' parents, spouses, relatives, employers, fellow employees, and health workers were feared and marginalized and denied access to their villages, their homes and property, health care, markets, water, and food. Patients, and even some nurses and doctors, fled hospitals when Ebola cases were brought in. Foreign countries cautioned their people to avoid travel to those countries of Ebola (Kabananukye, 2001, p. 12). The health care workers, especially those who worked in the isolation ward, were shunned by their families, colleagues, and community. Some were attacked and narrowly escaped death. Their properties and plantations were destroyed. Their spouses abandoned them. They were called the Ebola people. For those who survived a case of Ebola, the stigmatization continued: They were shunned and feared. One female survivor committed suicide because people so feared her they would run from her (Kabananukye, 2001, p. 14). People, and the nurses, were stigmatized and feared for simply knowing, let alone caring for, victims of Ebola. Survivors' children were not allowed to go to school. Families could not go to church, buy food at the local market, eat in a restaurant, rent homes, or even walk along certain paths. Health care workers, including the international teams, were among those most feared.

As in much of Africa, a general mistrust of Western Europeans exists and extends to the nurses who often worked with the international teams when they arrived. The health care workers were thought to be packing the sick into bags, alive or dead, placing them in coffins and selling them off to Europeans for profit. In Uganda, one nurse explained,

\footnotetext{
The work was difficult. Once a person was sick they were taken to the hospital and never seen again by their families. The people would not believe they would die, immediately after they died, they were put in body bags by the mobile teams (international teams), and the people were never allowed to see the body.
}

As noted, this and other such acts contributed to a general climate of fear and tension, and nurses too often became associated with the mistrusted Western Europeans.

$R O C$. Stigmatization of nurses was less pronounced in the recent ROC outbreak because, as noted, it was a rural outbreak; few patients were admitted to the clinics, and nosocomial transmission was minimal. However, local Red Cross volunteers trying to provide health education and follow contact cases, and the international and national teams, were in fact stigmatized because as some explained, Ebola came from secret meetings of academics associated with a group called the Rose Croix, often thought to be associated with the Red Cross. Initially, the lives of health care workers, including ours, were at risk because of their potential links to Rose Croix. Four schoolteachers were murdered just days before our arrival because local people felt they were linked to Rose Croix and, in part, responsible for the deadly outbreak. However, for the most part, the people and nurses of ROC responded differently than those in Uganda and DRC because this was the second outbreak they had experienced. The cultural models outlined moved from sorcery to epidemic relatively quickly in many parts of the region.

In spite of there having been an outbreak the previous year, the nurses and health workers working with patients with Ebola still experienced some form of stigmatization by their colleagues, families, and communities. Especially in the early phases of the outbreak, the nurses and health care workers in other units were especially fearful of nurses working in the isolation units. Other nurses would not talk to them or share food with them. At home, their families did not want to share anything the nurses touched-pots, pans, beds, bikes, or food. Many nurses in ROC bathed in bleach every night.

Although they were stigmatized at home, especially in Uganda, some nurses wanted to maintain that distance with 
family members; they were fearful that they could potentially infect their spouse and children. As one nurse stated, "I kept myself away from my family. I did not know the incubation period. But in case, I kept myself away, I did not want to infect my family and friends."

Finally, stigmatization is, in part, linked to some of the cultural models described above. In the ROC and Uganda, when the illness is identified as an epidemic and cultural protocols are activated to minimize contamination, it is likely that those associated with the disease, such as nurses and other caregivers, might be viewed as suspect. Traditionally, a person with gemo or opepe would be isolated and receive food and care at a distance. A survivor of the disease or elderly woman or man would be the caregiver.

\section{Commitment to the Profession}

The nurses and other members of the medical communities of the DRC, Uganda, and ROC were under enormous stress from many areas. However, they had to face not only stress and lack of equipment and pay but also the potential of being infected with the fatal virus themselves. They were placed at a high risk of infection during these outbreaks. The nonspecific signs and symptoms of the patients and the conditions under which the health care workers were giving care made them a highly exposed and very vulnerable group of caregivers. However, many continued to give care in the face of such circumstances. "In these outbreaks, provision of nursing care by health workers and household members was a risk factor for infection" (Roels et al., 1999, p. 96). The same risk factors faced by the general population were shared by the medical community; however, they were also amplified by the nature of the care they gave to the victims of Ebola. Simply showing up for work at the hospital, giving care, touching a patient unknowingly infected with the virus, taking blood, and giving injections all functioned to put health care workers at risk. The nurses often lacked proper training in effective barrier nursing techniques to combat this killer epidemic; they lacked even the simplest infectious control tools, such as gloves, bleach, soap, and water, with which to protect themselves. They were as vulnerable as the patients they were attempting to give care to. And yet in spite of that risk, their vulnerability, with little pay and great economic and political strain, the nurses continued to give care to those dying. And, like most anyone directly involved in the control of an Ebola outbreak, nurses and health care workers were fearful for their own lives.

We are afraid. We question our safety. But we are obliged to our patients. (Congolese nurse)

We take precautions, we know of this illness, but all we can do is pay attention. If we could see the sickness, like we can see a car, then everyone would be safe, but it is a virus we cannot see. We have fear. (Congolese nurse)
What emerged from the interviews, repeatedly, is that despite the profound fear, lack of resources with which to protect themselves, and stigmatization suffered at work and home, many nurses were clearly committed to their profession.

They (the burial team) are volunteers who are doing this of their own free will.... No one from the government has told them to. They are willing to die for others. (Garrett, 2000, p. 82)

At first I felt very bad, I did not know about Ebola, I was not told much. But I overheard a rumor about this deadly disease that kills. I prayed to God about if I died, but it was a part of my work. There was no way for me to refuse. To refuse would be very bad, I am the head nurse of the ward, and it would be very difficult for the others to continue. Some nurses quit because their husbands wanted to reject them. I did not refuse. (Ugandan nurse)

\section{DISCUSSION AND CONCLUSIONS}

The data on nurses presented here are the first to focus on nurses and health care workers during a rapid killer epidemic. The current study is limited because relatively few nurses were interviewed because they were only one part of a broader study of the cultural contexts of EHF. The data are also limited because of being collected during a relatively short period of time (a few weeks at each site) because WHO and other medical teams wanted the data as quickly as possible.

Nurses were fearful for their own lives, their families' lives; they lacked protective gear, had few resources, families and colleagues shunned them-but they remained committed to their profession. They wanted to serve. As they had some biomedical training and knowledge, which made them feel somewhat less vulnerable, they wanted to use this knowledge to try to stop a rapid killing disease. Nurses in ROC expressed the importance of knowledge because with knowledge, stigmatization decreased and cooperation increased. Knowledge enabled us and other national and international health care workers to feel secure and provide assistance in spite of being surrounded by our own and other's fears.

These nurses demonstrated what it means to work with dedication and strength. They manifested the resiliency of the human spirit - about what it means to give care in the face of death. And as Kabananukye (2001) also pointed out,

Nurses should be duly recognized as an important cadre of medical care. . . The late doctor . . . who died of Ebola, received international recognition with grants (for) his family, yet the fourteen nurses who died with him, their families and children were not remembered.... There is a bias towards nurses as being inferior partners to medical doctors. (p. 28) 
Local nurses are a vital resource in the control of disease. They are a part of the indigenous culture and, therefore, have some understanding of indigenous values, beliefs, and behaviors. At the same time, they are trained within biomedical models and systems of care. They can and do negotiate and work within the different cultural models as they are being modified throughout the period of the epidemic. Hopefully, this research demonstrates the potential benefits of indigenous cultural models so local nurses do not feel that their beliefs are without value and that international teams will listen more closely to local nurses and communities.

Ebola outbreaks have generated worldwide interest, in part, because of the popular success of Richard Preston's book, The Hot Zone, and the subsequent movie, Outbreak. However, this interest is also a consequence of human nature, when fear and a desire for knowledge emerge whenever we are faced with an illness that causes multiple rapid deaths. However, it is also the realization of the permeability of national and international borders with regard to disease that was made evident during the SARS epidemic. There is not only a globalization of economies but also a globalization of diseases. With the ease of international travel of both people and disease, what happens during an outbreak in a remote village in Africa can no longer be ignored. An opportunity is provided within which to learn valuable lessons in how to deal more effectively with disease control.

\section{REFERENCES}

Farmer, P. (2005). Pathologies of power: Health, human rights and the new war on the poor. London: University of California Press.

Formenty, P. F., Fibamam, A., Epelboin, Y., Allarangar, E., Leroy, H., Moudzeo, P., et al., et l'equipe de lutte contre epidemie d'Ebola au Congo [and the Ebola Epidemic Control Team in the Congo]. (2003). L'epidemie de fievre hemorragique a virus Ebola en Republique de Congo, 2003: Une nouvelle strategie [Ebola hemorrhagic fever virus epidemic in the Republic of the Congo 2003: A new strategy]. Medecine Tropicale, 6, 291-295.

Garrett, L. (2000). Betrayal of trust, the collapse of global public health. New York: Hyperion.
Guimard, Y., Bwaka, M. A., Colebunders, R., Calain, P., Massamba, M., Deroo, A., et al. (1999). Organization of patient care during the Ebola hemorrhagic fever epidemic in Kikwit, Democratic Republic of Congo. Journal of Infectious Disease, 179(Suppl. 1), S268-S273.

Hewlett, B., \& Amola, R. (2003, March 15). Culture and Ebola in northern Uganda. Emerging Infectious Diseases, 9, 1242-1248.

Kabananukye, K. I. B. (2001). Denial, discrimination and stigmatization: The case of Ebola epidemic in some districts. Kampala, Uganda: Makerere University.

Kleinman, A. (1980). Patients and healers in the context of culture: An exploration of the borderland between anthropology, medicine, and psychiatry. Berkeley: University of California Press.

Peters, C. J., \& LeDue, J. W. (1999). An introduction to Ebola: The virus and the disease. Journal of Infectious Disease, 179(Suppl. 1), vi-xv.

Roels, T. H., Bloom, A. S., Buffington, J., Muhungu, G. L., MacKensie, W. R., Khan, A. S., et al. (1999). Ebola hemorrhagic fever, Kikwit, Democratic Republic of the Congo, 1995: Risk factors for patients without a reported exposure. Journal of Infectious Disease, 179(Suppl. 1), S92S97.

World Health Organization. (2003). Outbreaks of Ebola haemorrhagic fever, Congo and Gabon, October 2001-July 2002. Weekly Epidemiological Review, 78, 217-224.

Bonnie L. Hewlett, PhD, RN, is an adjunct professor of anthropology at Oregon State University. She received her Ph.D. in anthropology from Washington State University, Vancouver, Washington (2004) and her degree in nursing (Registered Nurse) from Clark College (1985), Vancouver, Washington. She is interested in adolescent health and development, medical anthropology, and the cultural contexts of infectious disease. Her publications include "Vulnerable Lives" in Hunter-Gatherer Childhoods (edited with B. S. Hewlett and M. Lamb, 2005) and is coauthor of Emerging Disease: Ebola, Culture and Politics (with B. S. Hewlett, in press).

Barry S. Hewlett, PhD, is a professor of anthropology at Washington State University. He was educated at California State University, Chico (B.A., 1971) and University of California, Santa Barbara (Ph.D., 1987). He is interested in parent-child relations, evolutionary cultural anthropology, and cultural contexts of infectious disease. His publications include Hunter-Gatherer Childhoods (edited with B. L Hewlett and M. Lamb, 2005) and Intimate Fathers (1991) and appeared in a special supplement to Tropical Medicine and International Health(with J. Koss-Chioino, 1997). 